\title{
Memory for pragmatic implications from courtroom testimony
}

\author{
RICHARD J. HARRIS, R. ROSS TESKE, and MARTHA J. GINNS \\ Kansas State University, Manhattan, Kansas 66506
}

\begin{abstract}
Subjects heard an excerpt of mock courtroom testimony and were later asked to rate statements about material in the testimony as "true," "false," or "of indeterminate truth value." Half of the subjects heard a given piece of information ( $\mathrm{Mr}$. X rang the burglar alarm) directly asserted (I rang the burglar alarm), while the other half heard it only pragmatically implied or suggested (I ran up to the burglar alarm). Half of the subjects initially heard specific instructions about the pitfalls of interpreting pragmatically implied information as if it were asserted fact, while the other half had no such instructions. Half of the subjects performed the response task immediately after hearing the testimony, while the other half did so 2 days later. Subjects generally remembered both implications and assertions as definite fact, even when specifically warned not to do so.
\end{abstract}

Studies in sentence memory during the past decade have shown a variety of distortions of linguistic input between presentation and recognition or recall. Although most such distortion is meaning preserving. some is not. One systematic and clearly non-meaning-preserving shift to occur widely in sentence memory is the recall or recognition of what was pragmatically implied instead of what was directly stated. Harris (1975) discusses pragmatic implication, which exists when an utterance "leads the hearer to expect something neither explicitly stated nor necessarily implied" in the sentence. For example, "the hungry python caught the mouse" pragmatically implies that the snake ate the mouse, although the mouse may have escaped before becoming the snake's dinner.

A number of recent laboratory studies have found that subjects often remember not what is directly stated in a sentence but, rather, what is pragmatically implied by it. This result has been found with cued recall (Brewer, 1974; Brewer \& Lichtenstein, 1975), recognition memory (Johnson, Bransford, \& Solomon, 1973), and true-false judgments of related sentences (Harris, 1974). For example, in a task where subjects judged a list of sentences as "true," "false," or "of indeterminate truth value" based on 32 prior input sentences, Harris (1974) found that a sentence like "the prisoner crawled under the barbed wire" was judged true whether the subject had heard "the prisoner managed to crawl under the barbed wire," which necessarily implies the previous sentence to be true, or "the prisoner was able to crawl under

This work was supported by a grant to the first author from the Kansas State University Faculty Research Award Committee. Appreciation is expressed to Virginia Dicks for running subjects and to Dennis Blair for his helpful comments on an earlier draft of the manuscript. A more complete report of this study is available from Richard J. Harris, Department of Psychology, Anderson Hall, Kansas State University, Manhattan, Kansas 66506. the barbed wire," which only pragmatically implies it to be true. Assertions and pragmatic implications were, however, discriminated when such a task was performed immediately after hearing the sentence instead of from memory.

An applied setting where the distinction between direct assertions and pragmatic implications could be critical is the recall of courtroom testimony by a jury during deliberation. If the memory distortions that occurred in the laboratory also occur in the courtroom setting, it could have serious consequences for the implementation of justice through the trial, where the jury is to evaluate the facts, not what the facts suggest.

Loftus and her associates (Loftus, Altman, \& Geballe, in press; Loftus \& Palmer, 1974; Loftus \& Zanni, 1975) have recently shown that a leading question may pragmatically imply certain information and distort a witness's memory for some time after the event. Subjects viewed a film and were afterwards interrogated with either leading or nonleading questions. Both immediately, and 1 week later, the subjects reported having seen what was implied by the leading question rather than what had actually been present.

In fact, the devious use of pragmatic implication in the courtroom has long been practiced by both lawyers and witnesses. A witness is liable for perjury for false assertions but not for false implications, even if these implications may be remembered by the jury as asserted facts. All character witnesses are introduced not for what their testimonies assert but rather what is implied about the defendant's guilt or innocence. Lawyers may attempt to introduce blatantly improper evidence or ask clearly leading questions, with the full knowledge that they will be immediately ruled out of order but not before the jury has heard the information and processed the pragmatic implications. 
Table 1

Mean Number of True Responses (Out of Nine) on Assertion and Implication Items

\begin{tabular}{|c|c|c|c|c|}
\hline \multirow[b]{3}{*}{$\begin{array}{l}\text { Instructions } \\
\text { Group }\end{array}$} & \multicolumn{4}{|c|}{ Delay Group } \\
\hline & \multicolumn{2}{|c|}{ Immediate } & \multicolumn{2}{|c|}{ 2-Day } \\
\hline & $\begin{array}{l}\text { Asser- } \\
\text { tion }\end{array}$ & $\begin{array}{l}\text { Impli- } \\
\text { cation }\end{array}$ & $\begin{array}{l}\text { Asser- } \\
\text { tion }\end{array}$ & $\begin{array}{l}\text { Impli- } \\
\text { cation }\end{array}$ \\
\hline No Instructions & 7.50 & 6.96 & 6.96 & 6.21 \\
\hline Instructions & 7.25 & 6.00 & 6.96 & 6.54 \\
\hline
\end{tabular}

The purposes of the present study were to extend the findings about memory for pragmatic implications of verbal material to the quasi-applied setting of a mock courtroom trial, to examine the course of such memory over time, and to test the effect of specific instructions to the "jury" to be wary of interpreting implications as assertions.

\section{METHOD}

The subjects were 96 undergraduate psychology students from Kansas State University; they received extra course credit for participation and were run in small groups.

A 5-min segment of mock trial testimony was constructed. At the beginning of the testimony the witness, a male investment broker at a securities firm, is sworn in; the rest of the tape consists of one attorney's questions and the witness's answers. The testimony concerns the witness's discovery of an apparent burglary, which he comes upon one evening on returning to work after dinner. The questions concern such events as the appearance of the office, actions of the witness, and the arrival of the police. In the testimony of the witness are 18 key sentences, each of which can occur in two alternate forms, one a direct assertion of some piece of information and the other a pragmatic implication of that same information. Two sample assertion statements were "that absent-minded Herman lost his walkie-talkie too" and "I walked away without taking any money," while the corresponding implication items were "that absent-minded Herman didn't have his walkie-talkie either" and "I was able to walk away without taking any money." Two tapes of the testimony were recorded, with every critical sentence which appeared as a direct assertion in Tape 1 occurring as a pragmatic implication in Tape 2 , and vice versa. There were nine direct assertions and nine pragmatic implications on each tape.

The experiment was a 2 by 2 by 2 design with a within-subjects variable of item type (direct assertion or pragmatic implication) and two between-subjects variables of instructions type (no instructions or implication instructions) and testimony-judgment delay (immediate or 2 days). Half of the subjects in each instructions group were questioned about the testimony immediately after its presentation, and the other half returned 2 days after hearing the tape to answer the questions. Half of the subjects in each instructions by delay group heard Tape 1 , and half heard Tape 2 .

All subjects were told that they were participating in a study of how people evaluate evidence presented in a jury trial. They were told to pretend that they were on the jury and listen to the trial excerpt, after which they would be asked some questions about what they had heard. The no-instructions subjects then heard either Tape 1 or 2 , while the implication-instructions subjects first heard eight paragraphs of additional instructions. The first two and the last two paragraphs w'ere very general instructions actually given by judges to juries in the District Court of Riley County, Kansas. Paragraphs 3-6, however, were written especially for the study and were as follows:

There are many ways to influence your memory on what is said and what happens in the courtroom. An implicating statement, question, or presentation is extremely effective in influencing your opinions and memory.

An example of an implicating statement is "The hungry python caught the mouse." This suggests that the snake ate the mouse and the statement will probably be remembered that way; that is, that he ate the mouse. The statement did not say the snake ate the mouse; it only highly suggested that he did. In court it is more likely that you will hear a statement like "The speeding car hit the pedestrian." This suggests that the car hurt the pedestrian, while in fact the car may have had its brakes applied and only tapped the pedestrian. Many times the implication is more subtle. For example, consider the difference between "The mother's child was killed" and "The patient's fetus was killed," the first implying that the unborn was a legal person but the second implying that the unborn was not a person.

An example of an implicating question is "Do you still beat your wife?" This suggests the recipient of the question has beaten his wife before, even if he answers "no" to the question. Even a minor change in a sentence or question can make a big difference. For example, the question, "Did you see the broken headlight?" suggests there was a broken headlight and asks if you saw it, when it would have been more proper to ask "Did you see a broken headlight?" meaning there might have been a broken headlight and asking if by chance you saw such an object.

You can be influenced by a leading question or any implicating presentation even if it is sustained or considered invalid. A question or presentation can influence your comprehension and memory by the implications it implies. The implication may influence you to believe what the attorney or witness wants you to believe. Implications can also influence the witness as well as you. You must be alert so that you will not be affected by implications but only affected by facts.

Immediately after the tape was finished, the no-delay subjects were given an answer sheet containing 36 statements which they were to judge (based on the taped testimony) as "true," "false," or "indeterminate" (tape did not make clear if true or false). Judgment sentences for the above two examples were "Mr. Ransom walked away from the office safe without taking any money, after he found the safe open" and "Herman Lyons, the night watchman, had lost his walkie-talkie." The 2-day-delay subjects performed the same task 2 days after hearing the tape. The 18 even-numbered items were statements that were either directly asserted or pragmatically implied by the testimony. These statements occurred in the order in which that information had occurred in the testimony. The 18 odd-numbered items consisted of nine statements that were clearly false, based on the testimony, and nine which were not mentioned in the testimony and thus should be checked indeterminate in truth value. These false and indeterminate items were included to prevent an otherwise strong response bias toward true responses. The subjects worked through the task at their own rate of speed.

\section{RESULTS}

Table 1 summarizes the mean number of true responses to assertion and implication items by subjects in the instructions by delay groups. An analysis of variance treating both subjects and items as random factors (Clark, 1973) was performed on the number of true responses on the 18 critical sentences. None of the main effects or interactions was significant at the .05 level, although there were nonsignificant trends toward fewer true responses to implication items in the instructions group with no 
delay, fewer true responses to implication than assertion items, and fewer true responses after 2 days than immediately.

\section{DISCUSSION}

The results of this study offer discouraging reflections of jurors' memories of courtroom testimony. Just as subjects did in the straight laboratory studies (Brewer, 1974; Brewer \& Lichtenstein, 1975; Harris, 1974; Johnson et al., 1973), subjects in the present study remembered pragmatic implications as if they were direct assertions. In fact, the overall mean across groups was $71.4 \%$ of the pragmatic implications judged as definitely true (vs. $79.6 \%$ of the assertions), and the lowest cell mean (instructions-no delay) was $66.7 \%$ implications recalled as true. Although there was an ordinal difference in the direction of fewer true responses to implication than assertion items, this difference was not significant at the .05 level.

What is even more surprising is that explicit instructions about the pitfalls of treating implications as assertions had at best only a limited effect. While neither the instructions main effect, the Instructions by Item Type interaction, nor the triple interaction was significant, there appeared to be a weak trend for instructions to reduce the number of "true" responses to implications in the no-delay condition, thus suggesting that instructions may slightly improve discrimination of assertions and implications. This trend, however, was not apparent in the 2-day-delay group.

The failure of the observed trends to reach statistical significance may be in part due also to the small number of items (18), with which the effects must be very large to be reliably generalizable to the entire population using the Clark (1973) analysis of variance. There was a relatively large variance among the items, especially in the case of implication items, where responses to some appeared to be greatly affected by the instructions and others not at all, although such differences did not appear to be related to intuitive similarities and differences across items.

In terms of a real courtroom situation, one can only speculate that, with longer time intervals and far more additional information to interfere, the confusion of pragmatic implication and asserted fact is widespread. Attorneys and judges should be alert to the assertion-implication distinction and insist on a witness's clarification when he utters potentially critical testimony in the form of a pragmatic implication. If he is not willing to directly assert the information in question, and thus make himself liable for perjury if he is willfully prevaricating, this disposition should be made abundantly clear to the jury. If the uttered implication is understood by the witness to be fact, then it should be so unambiguously stated.

\section{REFERENCES}

BREWER, W. F. Memory for the pragmatic implications of sentences. Unpublished manuscript. 1974. Available from Department of Psychology, University of Illinois, Champaign, Illinois 61820.

Brewer, W. F., \& Lichtenstein, E. H. Recall of logical and pragmatic implications in sentences with dichotomous and continuous antonyms. Memory \& Cognition, 1975, 3, 315-318.

Clark, H. H. The language-as-fixed-effect fallacy: A critique of language statistics in psychological research. Journal of Verbal Learning and Verbal Behavior, 1973, 12, 335-359.

HARRIS, R. J. Memory and comprehension of implications and inferences of complex sentences. Journal of Verbal Learning and Verbal Behavior, 1974, 13, 626-637.

HARRIS, R. J. The psychology of pragmatic implication. KSU Human Information Processing Institute Report No. 75-2, April, 1975. Available from Department of Psychology, Kansas State University, Manhattan, Kansas 66506.

Johnson, M. K., Bransford, J. D., \& Solomon, S. K. Memory for tacit implications of sentences. Journal of Experimental Psychology, 1973, 98, 203-205.

Loftus, E. F., Altman, D., \& Geballe, R. Effects of questioning upon a witness's later recollections. Journal of Police Science and Administration, in press.

Loftus, E. F., \& Palmer, J. C. Reconstruction of automobile destruction: An example of the interaction between language and memory. Journal of Verbal Learning and Verbal Behavior, 1974, 13. $585-589$.

LofTus, E. F., \& ZANNI, G. Eyewitness testimony: The influence of the wording of a question. Bulletin of the Psychonomic Society. 1975, 5. 86-88.

(Received for publication August 12, 1975.) 